\title{
Treatment persistence and cost-effectiveness
} of latanoprost/latanoprost-timolol, bimatoprost/ bimatoprost-timolol, and travoprost/travoprosttimolol in glaucoma: an analysis based on the United Kingdom general practitioner research database

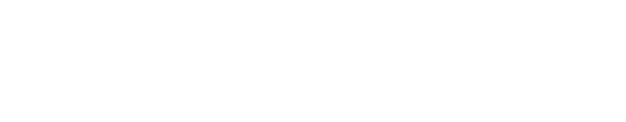

\section{Antoine Lafuma' John F Salmon ${ }^{2}$ \\ Julien Robert ${ }^{\prime}$ \\ Gilles Berdeaux ${ }^{3}$ \\ 'Cemka, Bourg-la-Reine, France; 2Oxford Eye Hospital, Oxford, UK; ${ }^{3}$ Conservatoire National des Arts et Métiers, Chaire Economie et Gestion des Services de Santé, Paris, France}

Correspondence: Antoine Lafuma Cemka-Eval, Health Economics Unit, 42 Boulevard du Maréchal Joffre, F-92340 Bourg-la-Reine, France

Tel +33 | 409 |30 33/+33 | 409 |303|

Email antoine.lafuma@cemka.fr
Objective: To compare treatment persistence and costs with 3 glaucoma treatment sequences (first-line/second-line): latanoprost/latanoprost-timolol (LLT), bimatoprost/bimatoprost-timolol (BBT), and travoprost/travoprost-timolol (TTT), derived from the UK General Practitioner Research Database (UK-GPRD).

Methods: Patient records referring to ocular hypertension, topical glaucoma treatment, surgery, or laser therapy were extracted. Patients prescribed LLT, BBT, or TTT sequences were selected. Treatment failure was inferred from glaucoma prescription change (adding or removing a topical treatment, surgery, or laser therapy). Treatment durations preceding failure were compared by applying Wilcoxon's test to survival curves. Adjustment on confounding variables was performed with a Cox model and a propensity score method. Unit costs were estimated from a UK National Health Service perspective.

Results: A total of 1592 patients received LLT, 110 BBT, and 114 TTT. Their mean age was 68 years and the sex ratio almost 1 male: 1 female. No significant demographic or comorbidity differences were observed between treatment sequences. Treatment persistence at 36 months was achieved in $60.0 \%$ of LLT, $55.5 \%$ of BBT, and $70.3 \%$ of TTT patients $(P=0.005)$. Resources consumed and associated monthly costs were significantly less for the TTT group (£17.74) compared with BBT (£21.30) and LLT (£22.37) groups.

Conclusion: Analysis of data obtained from the UK-GPRD suggests that the TTT treatment sequence achieved longer treatment persistence at lower cost than LLT and BBT.

Keywords: glaucoma, travoprost, timolol, latanoprost, bimatoprost, persistency, costs

\section{Introduction}

Primary open angle glaucoma (POAG) is a chronic optic neuropathy that can lead to blindness if untreated. ${ }^{1}$ Its cause is unknown, but raised intraocular pressure (IOP) is the main controllable risk factor. ${ }^{2}$ Among people registered as blind in the UK $10 \%$ to $11 \%$ suffer from glaucoma, ${ }^{3}$ corresponding approximately to 3400 new registrations per year. The overall prevalence of glaucoma in the population aged more than 40 years is approximately $2 \%,{ }^{4}$ amounting to nearly 500,000 people in England alone. The rate increases with age, rising to almost $10 \%$ of persons older 
than 75 years. The prevalence may be higher for those with a family history of glaucoma, or with African or Caribbean black antecedents. ${ }^{5}$ The most frequent diagnosis is POAG that develops slowly and becomes chronic. However, in about $50 \%$ of cases the condition remains undiagnosed. ${ }^{6}$ New cases of chronic POAG affecting persons aged 40 to 70 years were estimated at 9263 per year in England. ${ }^{7,8}$ It is estimated that $3 \%$ to $5 \%$ of those over 40 years have ocular hypertension, which equates to around 1 million people in England. ${ }^{8}$

Costs of glaucoma in UK working and elderly populations total $£ 38$ billion per year, with individual lifetime costs up to $£ 40,000 .{ }^{9}$ Observational data indicate a high frequency of treatment switches in glaucoma incurring increased costs. ${ }^{10,11}$ Although prescribers should consider the daily costs of a chosen drug, ${ }^{12}$ efficacy is also important as it may affect total costs, such as ophthalmological visits, laser therapy, or surgery. ${ }^{13-15}$

A recent British recommendation on POAG treatment is to 'offer people newly diagnosed with early or moderate POAG, and at risk of significant visual loss in their lifetime, treatment with a prostaglandin analogue' ${ }^{16}$ Hence, first-line treatment should comprise a single drug. Drug combinations are often prescribed after initial treatment failure. Accordingly, fixed combinations (eg, a prostaglandin analog with timolol) were developed as second-line treatment to simplify administration and improve compliance.

Intraocular pressure reduction by prostaglandin ana$\operatorname{logs}$, and the greater efficacy of travoprost and bimatoprost, compared with latanoprost, have been demonstrated by meta-analysis. ${ }^{17}$ However, because effectiveness in everyday practice does not necessarily reproduce the close follow-up of randomized clinical trials, a survey of field observations might help public health decision committees. Previous observational surveys by Denis et al have shown better first-line IOP control with travoprost than with latanoprost, and better second-line control with a travoprost and timolol fixed combination than with a latanoprost and timolol fixed combination. ${ }^{18,19}$ Also a discrete event simulation model showed that time elapsing before switching to third-line treatment was longer after travoprost/travoprost-timolol than latanoprost/ latanoprost-timolol, ${ }^{20}$ when the probability of treatment sequence switching was determined by extrapolation from 2 randomized clinical trials. ${ }^{21,22}$

Since health authorities increasingly require documentation on effectiveness based on daily prescription data, ${ }^{23}$ patients' medical records are a valuable source of information to compare everyday treatment strategies. This approach has already been applied to glaucoma treatment and the outcomes are often referred to as 'persistence' or 'adherence' to treatment. ${ }^{24-27}$

The United Kingdom General Practitioner Research Database (UK-GPRD) collects medical information reported by a representative sample of general practitioners (GPs). ${ }^{28}$ Specialized data on glaucoma are available because GPs serve as gatekeepers in the UK. The present study searched the UK-GPRD to compare the effectiveness and costs of 3 different treatment sequences in glaucoma patients, each sequence retaining its first-line prostaglandin analog in its second-line combination with timolol. The objective of this analysis was to compare treatment persistence and costs for the following 3 treatment sequences: 1) first-line latanoprost (Xalatan ${ }^{\circledR}$; Pfizer Inc, Bridgewater, NJ) with second-line latanoprost plus timolol (Xalacom ${ }^{\circledR}$; Pfizer Inc), ie, latanoprost/latanoprost-timolol); 2) first-line bimatoprost (Lumigan $^{\circledR}$; Allergan Inc, Brunswick, NJ) with secondline bimatoprost plus timolol (Ganfort ${ }^{\circledR}$; Allergan Inc), ie, bimatoprost/bimatoprost-timolol; and 3) first-line travoprost (Travatan $^{\circledR}$; Alcon Inc, Fort Worth, TX) with second-line travoprost plus timolol (DuoTrav ${ }^{\circledR}$; Alcon Inc), ie, travoprost/ travoprost-timolol.

\section{Patients and methods}

Data were extracted on primary care patients from the world's largest computerized database, the UK-GPRD, which stores anonymous longitudinal data on approximately 3 million patients treated by UK general practitioners since 1987. Records include information on age, gender, medical diagnosis, prescriptions, clinical events, and hospital referrals.

The glaucoma population was identified with terms that specified diagnosis, surgical interventions, and drug treatments, as follows:

1. Glaucoma diagnostic terms included specific 'open-angle' and more generic 'glaucoma' expressions. Patients were excluded when diagnoses specified 'closed-angle', 'angle closure', and 'glaucoma due to other causes', eg, trauma.

2. Surgery or laser therapy associated with specific glaucoma terms were flagged, eg, 'laser trabeculoplasty' or 'iridectomy for glaucoma'. Nonspecific interventions were excluded, eg, 'iridectomy' without a glaucoma term.

3. Glaucoma drugs were defined by their active constituents as listed in the British National Formulary [www.bnf.com]. Both topical and systemic formulations were included. 
The analysis focused on newly diagnosed patients treated for either glaucoma or ocular hypertension. Eligible patients were included when they fulfilled the following 3 criteria: 1) glaucoma diagnosis (as above); 2) follow-up longer than 6 months; and 3) treatment with one of the following first-line/ second-line treatment sequences: 1) latanoprost/latanoprosttimolol (LLT); 2) bimatoprost/bimatoprost-timolol (BBT); and 3) travoprost/travoprost-timolol (TTT). These treatment sequences were the only anti-IOP lowering agents allowed.

Because the UK-GPRD reports mainly incidence rates (such as visits, drugs, comorbidity) much data management was needed to extrapolate prevalence rates. The following hypotheses and rules were employed: 1) eye and general co-morbidities (ICD-10 codes) were extracted from the UK-GPRD from the start of glaucoma treatment, but were not necessarily present when glaucoma was first diagnosed; 2) treatment failure was defined as a prescription change, ie, replacing, discontinuing, or adding medication (association) after starting a treatment sequence; 3) patients undergoing laser therapy or surgery for glaucoma were also regarded as treatment failures; 4) the principal assumption was that topical POAG treatment (categorized by product name and prescription dates) was prescribed for a maximum of 100 days. Because practitioners rarely prescribed more than 3 eye-drop bottles (appropriate for 100 days), a treatment prescribed twice within 100 days was assumed to have been both renewed and continuous; 5) other topical preparations prescribed simultaneously during the foregoing periods were regarded as supplementary treatments. The last rule constituted the main evaluation criterion, ie, treatment failure. The economic analysis was applied to resource utilization during successful treatment as reported in the database.

Statistical analyses were performed with SAS V9.1 software (SAS Institute; NC, USA). Treatment sequences were compared at baseline with respect to demography, and general and eye comorbidities. Continuous variables were compared by a $t$-test when distributions were normal or, conversely, by Wilcoxon's nonparametric test. Discontinuous variables were analysed by a Chi-square test or by Fisher's exact permutation test when samples were small. All tests were interpreted 2-sided with $P=0.05$.

The study analyzed both direct medical costs and the consequences of glaucoma medical care from the economic perspective of the UK National Health Service. The database yielded information on glaucoma resource utilization as follows: 1) laser or surgical treatments, 2) hospitalizations, 3) medication, 4) medical visits to specialists and GPs, and 5) prescription renewals by telephone. Consumed items were collected for each patient from the first glaucoma prescription to the last follow-up day and included medication following treatment failures.

Medication costs were taken from the British National Formulary (2008) and did not take drug discounts into account. ${ }^{29}$ Unit costs relating to laser therapy and surgery were estimated from Department of Health tariffs. ${ }^{30}$ Visits to specialists ${ }^{31}$ and GPs, ${ }^{32}$ and prescription renewals by telephone ${ }^{33}$ were costed from two Personal Social Services Research Unit reports. Results are expressed as GBP, 2008.

Cost consequences of all 3 treatment sequences were estimated with and without adjustment and took into account duration of follow-up. Adjustment was made by a linear regression model.

\section{Results}

The UK-GPRD yielded a total of 69,360 glaucoma patients including 1816 who received the studied treatment sequences, ie, 1592 patients (LLT), 110 (BBT), and 114 (TTT).

Table 1 shows that the mean age of patients was 68 years with a sex ratio of approximately 1 male: 1 female. No demographic differences were observed between treatment sequences. The mean follow-up duration was longest for LLT patients, which is explained by earlier market access authorization.

Eye and general comorbidity characteristics are shown in Tables 2 and 3, respectively. No imbalance of eye comorbidity prevalence was observed between the 3 treatment sequences. Also, the prevalence rates of various general comorbidities were similar for all sequences, apart from less frequent vascular disorders in the LLT group $(57.9 \%$ versus $69.1 \%$ [BBT] and $68.4 \%$ [TTT]).

Percentages of patients remaining under treatment with the studied sequences were estimated at different time points (Table 4). At 36 months $60.0 \%$ of patients continued with the LLT sequence, compared with $55.5 \%$ with BBT, and $70.3 \%$ with TTT (Wilcoxon's test: $P=0.005$ ).

Logistic regression did not identify any potential confounding factor that would bias the time-to-failure differences above. Hence no adjustment was performed. Figure 1 presents all 3 survival curves.

Table 5 shows average monthly costs of resources consumed with the 3 treatment sequences. The economic analysis was applied to resources consumed during treatment and following failure. Treatment failure was experienced by 821 of 1592 LLT patients (51.6\%), 33 of 110 BBT patients (30.0\%), and 29 of 114 TTT patients (25.4\%). An additional treatment was prescribed for $40 \%$ of the TTT patients and a switch for $52 \%$. Laser therapy or surgery was performed on $2 \%$ of 
Table I Patient characteristics according to treatment sequence

\begin{tabular}{|c|c|c|c|c|}
\hline Patient characteristic & $\begin{array}{l}\text { Latanoprost/latanoprost- } \\
\text { timolol } \\
n=1592\end{array}$ & $\begin{array}{l}\text { Bimatoprost/bimatoprost- } \\
\text { timolol } \\
n=110\end{array}$ & $\begin{array}{l}\text { Travoprost/travoprost- } \\
\text { timolol } \\
\mathrm{n}=114\end{array}$ & $P$-value \\
\hline \multicolumn{5}{|l|}{ Gender } \\
\hline Male & $48.8 \%$ & $45.5 \%$ & $50.9 \%$ & 0.71 \\
\hline Female & $51.2 \%$ & $54.5 \%$ & $49.1 \%$ & \\
\hline Age (year) & 68.3 & 68.2 & 68.8 & 0.95 \\
\hline Time since diagnosis (years) & 4.34 & 4.24 & 3.57 & 0.12 \\
\hline Mean duration of follow-up (days) & 1584.46 & 638.19 & 798.94 & $<0.001$ \\
\hline
\end{tabular}

Table 2 Ocular comorbidities according to treatment sequence: reported numbers (\%)

\begin{tabular}{|c|c|c|c|c|}
\hline Comorbidities & $\begin{array}{l}\text { Latanoprost/latanoprost- } \\
\text { timolol } \\
n=1592\end{array}$ & $\begin{array}{l}\text { Bimatoprost/bimatoprost- } \\
\text { timolol } \\
n=110\end{array}$ & $\begin{array}{l}\text { Travoprost/travoprost- } \\
\text { timolol } \\
\mathrm{n}=1 / 4\end{array}$ & $P$-value \\
\hline $\begin{array}{l}\text { Anterior eye: structural } \\
\text { change, deposit, or } \\
\text { degeneration }\end{array}$ & 339 (21.7\%) & 27 (24.5\%) & 18 (I5.8\%) & 0.24 \\
\hline $\begin{array}{l}\text { Ocular infection, irritation, } \\
\text { or inflammation }\end{array}$ & 453 (29.0\%) & $28(25.5 \%)$ & 27 (23.7\%) & 0.37 \\
\hline Ocular injury & $13(0.8 \%)$ & $0(0.0 \%)$ & $0(0.0 \%)$ & - \\
\hline $\begin{array}{l}\text { Ocular neuromuscular } \\
\text { disorders }\end{array}$ & 83 (5.5\%) & $8(7.3 \%)$ & 5 (4.4\%) & 0.60 \\
\hline $\begin{array}{l}\text { Ocular hemorrhage and } \\
\text { vascular disorders NEC }\end{array}$ & 66 (4.2\%) & 2 (I.8\%) & $6(5.3 \%)$ & 0.39 \\
\hline Vision disorders & 290 (I8.6\%) & 19 (I7.3\%) & 17 (I4.9\%) & 0.60 \\
\hline
\end{tabular}

Abbreviation: NEC, not elsewhere classified.

Table 3 General comorbidities according to treatment sequence: reported numbers (\%)

\begin{tabular}{|c|c|c|c|c|}
\hline Comorbidities & $\begin{array}{l}\text { Latanoprost/latanoprost- } \\
\text { timolol } \\
n=1,592\end{array}$ & $\begin{array}{l}\text { Bimatoprost/bimatoprost- } \\
\text { timolol } \\
n=110\end{array}$ & $\begin{array}{l}\text { Travoprost/travoprost- } \\
\text { timolol } \\
n=1 / 4\end{array}$ & $P$-value \\
\hline $\begin{array}{l}\text { Blood and lymphatic } \\
\text { disorders }\end{array}$ & $190(12.2 \%)$ & $13(1 \mathrm{I} .8 \%)$ & $15(13.2 \%)$ & 0.94 \\
\hline Cardiac disorders & $810(51.9 \%)$ & $55(50.0 \%)$ & $62(54.4 \%)$ & 0.80 \\
\hline Ear and labyrinth disorders & $807(51.7 \%)$ & $55(50.0 \%)$ & $62(54.4 \%)$ & 0.80 \\
\hline Endocrine disorders & $337(21.6 \%)$ & $22(20.0 \%)$ & $24(21.1 \%)$ & 0.92 \\
\hline Gastrointestinal & 1072 (68.6\%) & $70(63.6 \%)$ & $84(73.7 \%)$ & 0.27 \\
\hline Hepatobiliary & 92 (5.9\%) & $6(5.5 \%)$ & $5(4.4 \%)$ & 0.79 \\
\hline Musculoskeletal and & $728(46.6 \%)$ & 57 (5I.8\%) & $59(51.8 \%)$ & 0.35 \\
\hline \multicolumn{5}{|l|}{ Connective tissue disorders } \\
\hline Nervous system disorders & $656(42.0 \%)$ & $48(43.6 \%)$ & $60(52.6 \%)$ & 0.08 \\
\hline Psychiatric disorders & $129(8.3 \%)$ & $10(9.1 \%)$ & $10(8.8 \%)$ & 0.94 \\
\hline Renal and urinary disorders & $681(43.6 \%)$ & 49 (44.5\%) & 47 (4I.2\%) & 0.86 \\
\hline Respiratory thoracic and & $655(41.9 \%)$ & 47 (42.7\%) & $5 \mathrm{I}(44.7 \%)$ & 0.84 \\
\hline \multicolumn{5}{|l|}{ Mediastinal disorders } \\
\hline Vascular disorders & 905 (57.9\%) & $76(69.1 \%)$ & $78(68.4 \%)$ & 0.009 \\
\hline
\end{tabular}

Table 4 Percentages of patients persisting with travoprost/travoprost-timolol, latanoprost/latanoprost-timolol, or bimatoprost/ bimatoprost-timolol as monotherapy, ranked according to treatment duration

\begin{tabular}{|c|c|c|c|}
\hline Treatment duration & $\begin{array}{l}\text { Latanoprost/latanoprost- } \\
\text { timolol } \\
n=1,592\end{array}$ & $\begin{array}{l}\text { Bimatoprost/bimatoprost- } \\
\text { timolol } \\
n=110\end{array}$ & $\begin{array}{l}\text { Travoprost/travoprost- } \\
\text { timolol } \\
n=|| 4\end{array}$ \\
\hline 12 months & $88.0 \%$ & $82.5 \%$ & $92.8 \%$ \\
\hline 24 months & $73.8 \%$ & $66.6 \%$ & $81.7 \%$ \\
\hline 36 months & $60.0 \%$ & $55.5 \%$ & $70.3 \%$ \\
\hline Time to $50 \%$ failure incidence rate & 48 months & 41 months & 62 months \\
\hline
\end{tabular}




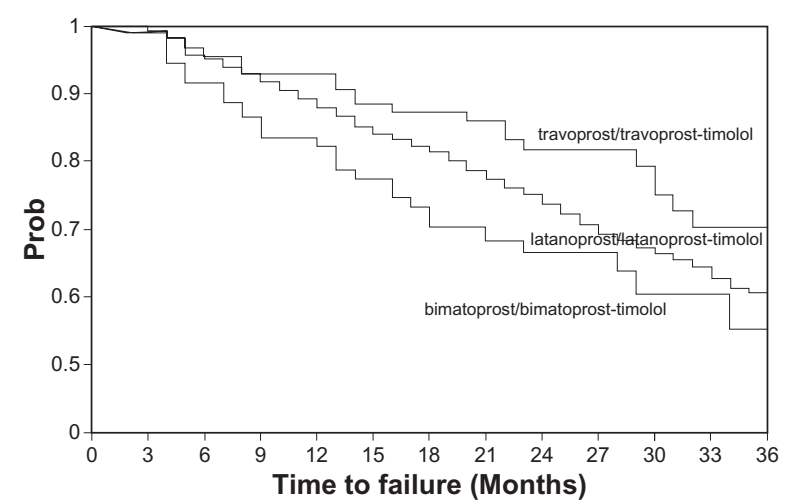

Figure I Time to treatment failure for travoprost/travoprost-timolol, latanoprost/ latanoprost-timolol, and bimatoprost/bimatoprost-timolol (follow-up was censored at 65 months).

patients. Average monthly costs of each treatment sequence were calculated for the entire observation period with adjustment on follow-up duration. Costs were significantly less with TTT than with LLT or BBT. The LLT sequence was significantly more costly than TTT or BBT. Most savings related to drug costs followed by visits. Adjustment on follow-up duration did not alter the results.

\section{Discussion}

We extracted information from the UK-GPRD on time elapsing to a third-line glaucoma treatment with 3 prostaglandin analogs, prescribed alone (first-line) and combined with timolol (second-line) in previously untreated patients presenting with ocular hypertension, POAG, or both conditions. In agreement with the literature we defined 'treatment failure' as the addition or removal of an IOP-lowering medication, or an intervention by laser therapy or surgery. Our analysis indicates that the average patient prescribed the TTT sequence switched significantly later to a third-line treatment, at lower cost, than patients given LLT or BBT. During the 5 years following treatment initiation the annual TTT failure rate was significantly less than the LLT and BBT rates.
The imbalance between the treatment groups is largely due to the fact that latanoprost had access to the market several years before the 2 other prostaglandin analogs, in monotherapy and as a timolol fixed combination. However, no major differences were observed between the 3 groups on the collected data, suggesting no major selection bias, although the statistical power of our tests was reduced by this unbalance. Whatever, we were able to show some differences in terms of treatment persistency.

Our retrospective analysis did not find demographic or comorbidity differences between treatment groups except for vascular disorders, which were less frequent in the LLT group. There is no obvious explanation for this imbalance, but since it was not associated with time to third-line treatment our conclusions are not altered.

A study of this nature has not been undertaken before. However, our results are supported by 2 previous reports. Both Netland et $\mathrm{al}^{21}$ and Topouzis et $\mathrm{a}^{22}$ observed trends suggesting better IOP control with travoprost. These results were confirmed by a meta-analysis, in which Denis et al showed better IOP control with travoprost or bimatoprost compared to latanoprost. ${ }^{17}$ In addition, our analysis reproduces the results of a model that extrapolated third-line treatment from randomized clinical trials. ${ }^{19}$

There are several limitations to this study. The main issue is a retrospective study design which precludes verification of data accuracy, causing internal validity to fall below the standard of a randomized clinical trial. Conversely, however, the UK health system confers practical advantages with longitudinal data collection, well-maintained documentation, and by limiting a patient's freedom to consult other physicians. Consequently, we were able to identify prior IOP-lowering treatment and ensure group comparability with a high degree of accuracy. Because reasons for modifying treatments are not documented in the UK-GPRD, it was necessary to assume that treatment changes were for reasons of tolerance or lack of

Table 5 Average monthly glaucoma costs according to treatment sequence $(£)$

\begin{tabular}{|c|c|c|c|c|}
\hline Cost item & $\begin{array}{l}\text { Latanoprost/latanoprost- } \\
\text { timolol } \\
\mathrm{n}=1592\end{array}$ & $\begin{array}{l}\text { Bimatoprost/bimatoprost- } \\
\text { timolol } \\
n=110\end{array}$ & $\begin{array}{l}\text { Travoprost/travoprost- } \\
\text { timolol } \\
\mathrm{n}=114\end{array}$ & $P$-value \\
\hline Drugs & 16.97 & 15.52 & 13.49 & $<0.0001$ \\
\hline Monthly consultation costs & 4.64 & 5.46 & 4.15 & 0.0004 \\
\hline $\begin{array}{l}\text { Monthly hospitalization- surgery-laser } \\
\text { therapy costs }\end{array}$ & 0.77 & 0.32 & 0.10 & 0.26 \\
\hline $\begin{array}{l}\text { Monthly total costs following } \\
\text { inclusion }(t)\end{array}$ & 22.37 & 21.30 & 17.74 & $<0.0001$ \\
\hline Mean daily costs & 0.75 & 0.71 & 0.59 & $<0.000$ I \\
\hline Adjusted monthly total costs & $22.46^{a}$ & $20.64^{b}$ & $\left.17.2\right|^{\mathrm{c}}$ & \\
\hline
\end{tabular}

Notes: ${ }^{\mathrm{a}} \mathrm{vs} \mathrm{b}^{\mathrm{b}}: 0.03 ;{ }^{\mathrm{a}} \mathrm{vs} \mathrm{c}^{\mathrm{c}}:<0.0001 ;{ }^{\mathrm{b}} \mathrm{vs} \mathrm{c}: 0.0004$ 
efficacy. Prescription renewals were not explicitly documented. However, as each eye-drop bottle contained enough fluid for 28 days,${ }^{34}$ including extra provision for patients with instillation difficulties, ${ }^{35}$ we fixed the average renewal period empirically at 100 days. Sensitivity analyses conducted on this parameter demonstrated the robustness of our findings.

Prospective, randomized clinical trials comparing such treatment sequences directly are unlikely to be performed because the follow-up would be long (at least 3 to 4 years); the number of patients needed per sequence to show a small difference would be high; the cost of such a trial would be significant, making its social utility questionable; and, finally, the relevance of such results would probably be challenged because prescribing habits might change with the arrival of new treatments or new scientific findings during the study. Therefore, a retrospective analysis of patients' medical records is a realistic alternative to a randomized clinical trial, even though its evidential value is less.

A retrospective analysis of existing data yields effectiveness estimates that are free of observational bias, although a treatment selection bias may occur when treatments are not randomized. Since no imbalances were found between the 3 treatment sequences, we did not have to perform adjustment when comparing treatment persistency.

\section{Conclusion}

According to UK-GPRD records, patients treated with travoprost/travoprost-timolol benefited from longer treatment persistence at costs significantly lower than those of latanoprost/latanoprost-timolol (26.1\%), or bimatoprost/ bimatoprost-timolol (16.3\%). First-line travoprost followed by second-line travoprost-timolol is a cost-effective sequence in everyday clinical practice.

\section{Acknowledgment}

This analysis was supported by a grant from Alcon. A poster was presented at The International Society for Pharmacoeconomics and Outcomes Research (ISPOR), Paris, November 2009 .

\section{Disclosure}

Dr Gilles Berdeaux is an Alcon Health Economist. None of the other authors declare any conflicts of interest.

\section{References}

1. Kingman S. Glaucoma is second leading cause of blindness globally. Bull World Health Organ. 2004;82:887-888.

2. Fechtner RD, Weinreb RN. Mechanisms of optic nerve damage in primary open angle glaucoma. Surv Ophthalmol. 1994;39:23-42.
3. Bunce $\mathrm{C}$, Wormald R. Leading causes of certification for blindness and partial sight in England \& Wales. BMC Public Health. 2006;6:58.

4. Weih LM, Nanjan M, McCarty CA, Taylor HR. Prevalence and predictors of open-angle glaucoma: results from the visual impairment project. Ophthalmol. 2001;108:1966-1972.

5. Rudnicka AR, Mt-Isa S, Owen CG, et al. Variations in primary open-angle glaucoma prevalence by age, gender, and race: a Bayesian meta-analysis. Invest Ophthalmol Vis Sci. 2006;47:4254-4261.

6. Topouzis F, Coleman AL, Harris A, et al. Factors associated with undiagnosed open-angle glaucoma: the Thessaloniki Eye Study. Am J Ophthalmol. 2008; 145:327-335.

7. Burr JM, Mowatt G, Hernández R, et al. The clinical effectiveness and cost-effectiveness of screening for open angle glaucoma: a systematic review and economic evaluation. Health Technol Assess. 2007;11(41):iii-iv, ix-x, 1-190.

8. Glaucoma: diagnosis and management of chronic open angle glaucoma and ocular hypertension. Costing Report, Implementing NICE guidance. NICE clinical guideline 85, April 2009.

9. An analysis of the costs of visual impairment and blindness in the United Kingdom issued by the Guide Dogs for the Blind Association. http://www.healthyeyes.org.uk/index.php?id=35\#894. Accessed August 13, 2010.

10. Kobelt G, Jonsson L, Gerdtham U, Krieglstein GK. Direct costs of glaucoma management following initiation of medical therapy. A simulation model based on an observational study of glaucoma treatment in Germany. Graefes Arch Clin Exp Ophthalmol. 1998;236:811-821.

11. Denis P, Lafuma A, Berdeaux G. Medical predictive factors of glaucoma treatment costs. J Glaucoma. 2004;13:283-290.

12. Jönsson B, Krieglstein G. Primary open-angle glaucoma-differences in international treatment patterns and costs. Oxford, Isis Medical Media LTTT; 1998.

13. Kooner KS, Zimmerman TJ. The cost of antiglaucoma medications. Ann Ophthalmol. 1987;19:327-328.

14. Baudouin C, Rouland JF, Le Pen C. Changes in medical and surgical treatments of glaucoma between 1997 and 2000 in France. Eur J Ophthalmol. 2003;13 Suppl 4:S53-S60.

15. Van der Valk R, Schouten JS, Webers CA, et al. The impact of a nationwide introduction of new drugs and a treatment protocol for glaucoma on the number of glaucoma surgeries. J Glaucoma. 2005;14:239-242.

16. Nice Guidance: Glaucoma: diagnosis and management of chronic open angle glaucoma and ocular hypertension. http://guidance.nice.org.uk/ CG85/. Accessed August 13, 2010.

17. Denis P, Lafuma A, Khoshnood B, et al. A meta-analysis of topical prostaglandin analogues intra-ocular pressure lowering in glaucoma therapy. Curr Med Res Opin. 2007;23:601-608.

18. Denis Ph, Launois R, Devaux M, Berdeaux G. Comparison of diurnal Intraocular pressure control by latanoprost versus travoprost: results of an observational survey. Clin Drug Investig. 2006;26:703-714.

19. Denis P, Lafuma A, Jeanbat V, et al. Intraocular pressure control with latanoprost/timolol and travoprost/timolol fixed combinations: a retrospective, multicenter, cross-sectional study. Clin Drug Investig. 2008;28:767-776.

20. Denis P, Le Pen C, Umuhire D, et al. Treatment carryover impacts on effectiveness of intraocular pressure lowering agents, estimated by a discrete event simulation model. Eur J Ophthalmol. 2008;18:44-51.

21. Netland PA, Landry T, Sullivan EK, et al; Travoprost Study Group. Travoprost compared with latanoprost and timolol in patients with open-angle glaucoma or ocular hypertension. Am J Ophthalmol. 2001;132:472-484.

22. Topouzis F, Melamed S, Danesh-Meyer H, et al. A 1-year study to compare the efficacy and safety of once-daily travoprost $0.004 \%$ / timolol $0.5 \%$ to once-daily latanoprost $0.005 \% /$ timolol $0.5 \%$ in patients with open-angle glaucoma or ocular hypertension. Eur J Ophthalmol. 2007; $17: 183-190$.

23. Hjelmgren J, Berggren F, Andersson D. Health Economics guidelines - Similarities, differences and some implications. Value Health. 2001;4:225-250. 
24. Covert D, Robin AL. Adjunctive glaucoma therapy use associated with travoprost, bimatoprost, and latanoprost. Curr Med Res Opin. 2006;22:971-976.

25. Deschaseaux-Voinet C, Lafuma A, Berdeaux G. Cost and effectiveness of brinzolamide versus dorzolamide in current practice: an analysis based on the UK-GPRD data base. J Med Econom. 2003;6:69-78.

26. Wilensky J, Fiscella RG, Carlson AM, et al. Measurement of persistence and adherence to regimens of IOP-lowering glaucoma medications using pharmacy claims data. Am J Ophthalmol. 2006;141(1 Suppl):S28-S33.

27. Nordstrom BL, Friedman DS, Mozaffari E, et al. Persistence and adherence with topical glaucoma therapy. Am J Ophthalmol. 2005;140:598-606.

28. General Practice Research Database. http://www.gprd.com/home/. Accessed on July 9, 2011.

29. British Medical Association. British National Formulary (BNF), No. 56. London: British Medical Association and the Royal Pharmaceutical Society of Great Britain; September 2008
30. Department of Health. Elective spell HRG Tariff 2009/10. London, UK: NHS.

31. Department of Health. NHS Reference costs 2006. http://www.dh.gov. uk/en/index.htm. Accessed August 13, 2010.

32. Curtis L. Unit Costs of Health and Social Care 2007. Canterbury, UK: PSSRU Personal Social Services Research Unit; 2007.

33. Curtis L, Netten A. Units costs of health and social care 2005 PSSRU University of Kent. http://www.pssru.ac.uk/. Accessed August 13, 2010.

34. Bergström A, Maurel F, Le Pen C, et al. Daily costs of prostaglandin analogues as monotherapy or in fixed combinations with timolol, in Denmark, Finland, Germany and Sweden. Clin Ophthalmol. 2009;3:471-481.

35. Stone JL, Robin AL, Novack GD, et al. An objective evaluation of eyedrop instillation in patients with glaucoma. Arch Ophthalmol. 2009;127:732-736.
Clinical Ophthalmology

\section{Publish your work in this journal}

Clinical Ophthalmology is an international, peer-reviewed journal covering all subspecialties within ophthalmology. Key topics include: Optometry; Visual science; Pharmacology and drug therapy in eye diseases; Basic Sciences; Primary and Secondary eye care; Patien Safety and Quality of Care Improvements. This journal is indexed on

Submit your manuscript here: http://www.dovepress.com/clinical-ophthalmology-journal

\section{Dovepress}

PubMed Central and CAS, and is the official journal of The Society of Clinical Ophthalmology (SCO). The manuscript management system is completely online and includes a very quick and fair peer-review system, which is all easy to use. Visit http://www.dovepress.com/ testimonials.php to read real quotes from published authors. 